\title{
Prevalence of Schistosomes and Soil-Transmitted Helminths among Schoolchildren in Lake Victoria Basin, Tanzania
}

\author{
Julius E. Siza', Godfrey M. Kaatano', Jong-Yil Chai ${ }^{2, *}$, Keeseon S. Eom³ ${ }^{3}$, Han-Jong Rim ${ }^{4}$, Tai-Soon Yong ${ }^{5}$, \\ Duk-Young Min ${ }^{6}$, Su Young Chang ${ }^{7}$, Yunsuk Ko ${ }^{7}$, John M. Changalucha ${ }^{1}$ \\ ${ }^{1}$ National Institute of Medical Research, P.O. Box 1462, Mwanza, Tanzania; ${ }^{2}$ Department of Parasitology and Tropical Medicine, Seoul National \\ University College of Medicine, Seoul 03080, Korea; ${ }^{3}$ Department of Parasitology and Medical Research Institute, Chungbuk National University \\ School of Medicine, Cheongju 28644, Korea; ${ }^{4}$ Department of Parasitology, College of Medicine, Korea University, Seoul 02841, Korea; ${ }^{5}$ Department \\ of Environmental Medical Biology and Institute of Tropical Medicine, Yonsei University College of Medicine, Seoul 03722, Korea; ${ }^{6}$ Department of \\ Microbiology and Immunology, Eulji University College of Medicine, Daejeon 35233, Korea; ${ }^{7}$ Good Neighbors International, Tanzania Western
}

Chapter, P.O. Box 367, Mwanza, Tanzania

\begin{abstract}
The objectives of this study was to conduct a survey on schistosomiasis and soil-transmitted helminth (STH) infections in order to come up with feasible control strategies in Lake Victoria basin, Tanzania. Depending on the size of the school, 150-200 schoolchildren were recruited for the study. Duplicate Kato-Katz stool smears were prepared from each child and microscopically examined for Schistosoma mansoni and STHs. Urine specimens were examined for Schistosoma haematobium eggs using the filtration technique. After the survey, mass drug administration was done using praziquantel and albendazole for schistosomiasis and STHs infections, respectively. A total of 5,952 schoolchildren from 36 schools were recruited for the study and had their stool and urine specimens examined. Out of 5,952 schoolchildren, 898 (15.1\%) were positive for S. mansoni, 754 (12.6\%) for hookworms, 188 (3.2\%) for Ascaris lumblicoides, and 5 $(0.008 \%)$ for Trichuris trichiura. Out of 5,826 schoolchildren who provided urine samples, 519 (8.9\%) were positive for S. haematobium eggs. The results revealed that intestinal schistosomiasis, urogenital schistosomiasis, and STH infections are highly prevalent throughought the lake basin. The high prevalence of intestinal and urogenital schistosomisiasis in the study area was a function of the distance from Lake Victoria, the former being more prevalent at localities close to the lake, whilst the latter is more so away from it. Control of schistosomiasis and STHs in the study area requires an integrated strategy that involves provision of health education to communities, regular treatments, and provision of adequate safe water supply and sanitation facilities.
\end{abstract}

Key words: Schistosoma haematobium, Schistosoma mansoni, soil-transmitted helminth (STH), schoolchildren, Lake Victoria basin, Tanzania

\section{INTRODUCTION}

World Health Organization (WHO) estimated that over 237 million people required treatment for schistosomiasis in 2010 [1] with estimates of up to an additional 779 million at risk globally [2]. Schistosomiasis is endemic in 76 countries worldwide and besides malaria is the second important parasitic disease for public health $[3,4]$. Of the 662 million people infected worldwide, $85 \%$ are from Africa [5]. In Tanzania, schis-

\footnotetext{
- Received 23 July 2015, revised 30 September 2015, accepted 4 October 2015.

*Corresponding author (cjy@snu.ac.kr)

(C) 2015, Korean Society for Parasitology and Tropical Medicine

This is an Open Access article distributed under the terms of the Creative Commons

Attribution Non-Commercial License (http://creativecommons.org/licenses/by-nc/3.0) which permits unrestricted non-commercial use, distribution, and reproduction in any

medium, provided the original work is properly cited.
}

tosomiasis is highly endemic, and its prevalence varies from one region to another, with a prevalence of up to $80 \%$ in highly endemic areas [6]. Intestinal schistosomiasis is caused by Schistosoma mansoni, and infections are acquired by contact with freshwater containing parasite larvae. The disease is hyper-endemic in the Great Lake regions of East Africa, owing to the favorable habitat for snails of the Biomphalaria genus, which are the intermediate host [7]. Recent studies around Lake Victoria indicated that the prevalence in schoolchildren vary widely [8-12]. In endemic areas, initial infection is acquired at a young age. Verani et al. [13] found that $14 \%$ of 1-year-old children along the Kenyan shores of Lake Victoria were S. mansoni positive, whereas Odogwu et al. [14] found a prevalence of $47.4 \%$ in children $<3$ years of age around Lake Victoria in Uganda. The prevalence in school-aged children in 
these areas could be as high as $86-90 \%$ [15].

In children, schistosomiasis normally presents with generalized, non-specific signs and symptoms, making it difficult to identify disease-specific morbidity indicators and challenging to develop tools for assessing those indicators. Over time, morbidity may progress from subtle manifestations such as anemia, to severe, debilitating, and irreversible conditions such as growth stunting, impaired cognitive development, increased susceptibility to co-infection, decreased quality of life, exercise intolerance, infertility, portal hypertension, and liver failure [16-22].

WHO estimated that more than a billion people are chronically infected with soil-transmitted helminths (STHs) [23]. Ascaris lumbricoides, hookworms (Ancylostoma duodenale and Necator americanus), and Trichuris trichiura are the most common STH species with global prevalence of about 1,000, 9001,300, and 500 million people, respectively [24-26]. As such, STH infections are still considered to be the most prevalent infections of mankind. Nowadays, STH has been classified among the most prevalent neglected tropical diseases (NTDs) as they persist exclusively in the poorest populations [27].

Often, schistosome infections co-occur with STHs. Findings from a study done among schoolchildren in a Lake Victoria shore line ward in Tanzania showed that the prevalence of hookworms was the second to intestinal schistosomiasis $[6,28]$. In Kenya, the prevalence of STHs is prominently attributed to $A$. lumbricoides, hookworms, and T. trichiura [29,30]. Hookworm infections observed in the lake basin in both Tanzania and Kenya were similarly high, ranging from $37.0-42.5 \%$ [10,31]. Other studies in Magu District, Tanzania, reported a prevalence of ascariasis of $<1 \%$ [10], and Handzel et al. [31] reported in Kenya's Nyanza Province the prevalence of $22.9 \%$ and $17.9 \%$ for A. lumbricoides and T. trichuris, respectively.

Possible factors associated with STH infections among the studied children included age (school-age), absence of toilet and piped water supply in the household, large family size ( $\geq 7$ members), and not washing hands before eating and after defecation [32].

Although helminths can infect all members of a population, there are specific groups who are more vulnerable and at a greater risk of infection [33,34]. For schistosomes and STHs, the most vulnerable groups are preschool children, schoolaged children, and women of child-bearing age, including adolescent girls although much of the morbidity associated with infection can be reversed with the use of effective anthelmintic drug treatments $[35,36]$.

Preschool children and school-aged children including adolescents tend to harbor the greatest numbers of intestinal worms and schistosomes and as a result experience growth stunting and diminished physical fitness as well as impaired memory and cognition [37]. These adverse health consequences combine to impair childhood educational performance, reduce school attendance [37], with hookworms being wellknown causes of anemia because of intestinal blood loss [38].

Chemotherapy with praziquantel (PZQ) is currently the mainstay of control, which is available at a low cost $[39,40]$. Moreover, due to their geographical overlap between schistosomes and STH infections, they could be simultaneously treated with 2 drugs, albendazole and praziquantel [41]. As such, the successful STH control programmes have enormous benefits of improved nutritional and health status of the children, higher educational attainment, labor force participation, productivity, and income among the most vulnerable populations [42-44]. An added externality is the impact that NTDs have on HIV/AIDS, tuberculosis, and malaria. Several recent papers highlight the immunosuppressive features of helminths (especially the STHs, schistosomes, and filariae) and their possible impact on promoting susceptibility to the big 3 diseases $[45,46]$. New data suggest that control of NTDs could become a powerful tool for combating HIV/AIDS, tuberculosis, and malaria [47]. This paper presents data using a rapid assessment methodology to examine the prevalence of schistosomiasis and STH infections in schools around the Tanzania perimeter of Lake Victoria.

\section{MATERIALS AND METHODS}

\section{Study area and population}

The study area is located on the northwest of Tanzania around Lake Victoria (Fig. 1). It stretches from the southwest of the lake through south to the eastern side. The area is comprised of Kagera, Mwanza, Mara on the lake shore, and Shinyanga about $60 \mathrm{~km}$ away from the lake. The study area is bordered by Uganda and Rwanda in the north and west, respectively. It is also bordered by Tabora and Manyara regions in the south and east, respectively. The main ethinic groups are; Wahaya and Wasubi in Kagera region, Wasukuma, Wazinza, and Wasumbwa in Mwanza region, Wajita, Wakurya, and Waluo in Mara region, and again Wasukuma and Wasumbwa in Shinyanga region. The major occupations of these people are peasant farming, pasto- 


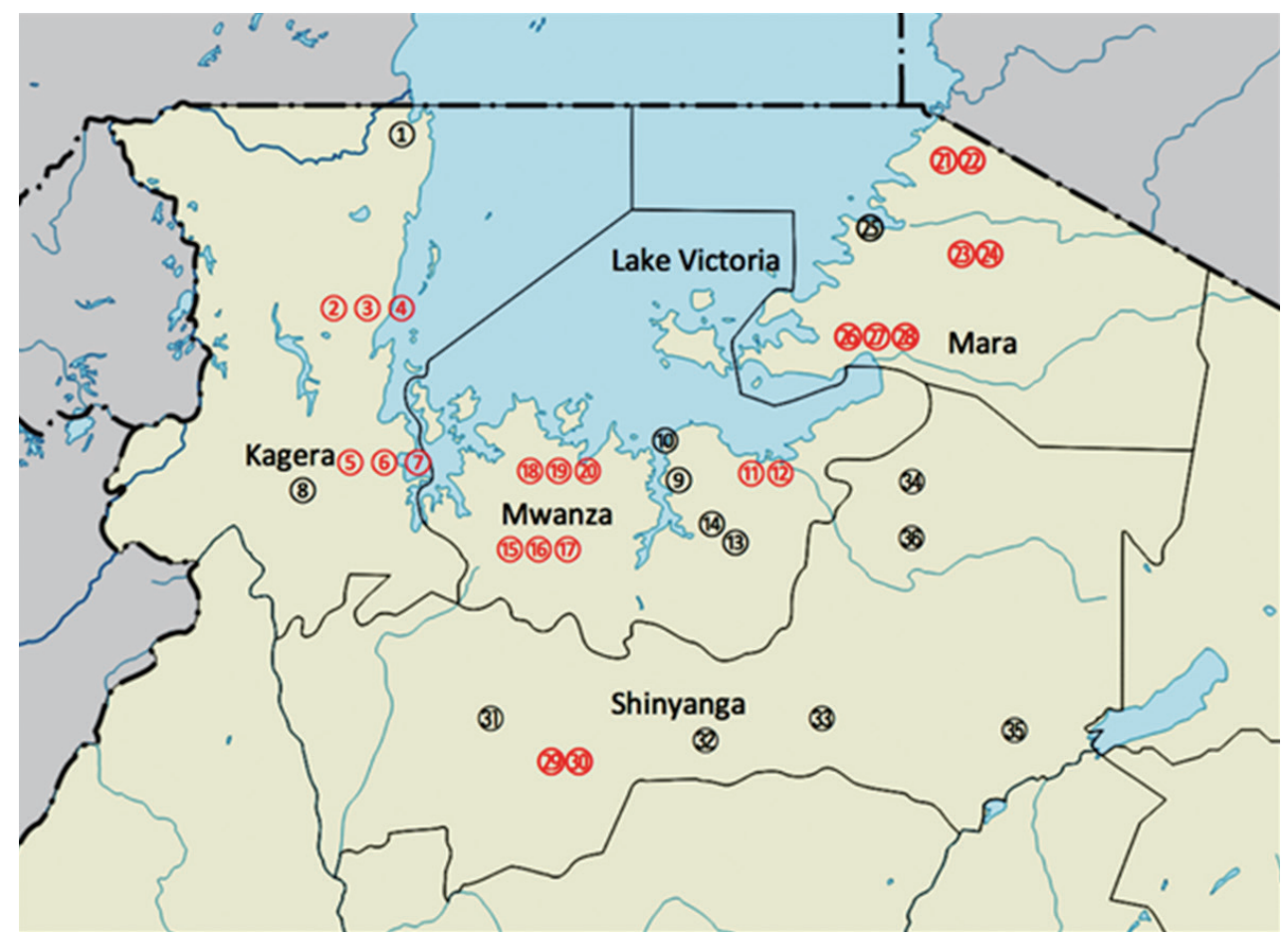

Fig. 1. Map of the study areas. Localities in Kagera region (1. Bunena, 2. Kiziramuyaga, 3. Kyenshama, 4. Nyairigamba, 5. Buzirayombo, 6. Bwanga, 7. Bwina, and 8. Runazi), Mwanza region (9. Tumaini, 10. Mazoezi, 11. Lumeji, 12. Nyamikoma, 13. Mwaging'hi, 14. Kigongo, 15. Bugogo, 16. Chibingo, 17. Kasamwa, 18. Nyakalilo, 19. Bungonya, and 20. Busisi), Mara region (21. Gamasara, 22. Ochuna, 23. Marasibora, 24. Minigo, 25. Mwisenge, 26. Guta "A", 27. Nyamitwebili, and 28. Bulamba), and Shinyanga region (29. Mseki, 30. Bukomela, 31. Masumbwe, 32. Luhumbo, 33. Songwa, 34. Shishiyu, 35. Ngugunu, and 36. Sapiwi).

ralism, and fishing. Much of the activities have a bearing to schistosomiasis and STH infections as they performed without protective gear in the area where the level of sanitation and hygiene is as low as in any poor resource settings.

\section{Specimen collection and examinations}

Collection of stool and urine specimens was done at the selected schools. Each child was given 1 stool container and 1 urine container on the first day and asked to bring the urine and stool specimens. The stool samples collected were processed to make duplicate Kato-Katz thick smears [48]. The smears were examined for hookworms and other helminth eggs or larvae within $1 \mathrm{hr}$ after preparation in order to capture hookworm eggs before they hatch. Examination for S. mansoni eggs was done a few minutes later. The egg counts on each of the 2 slides were added together and divided by 2 to get the mean number of egg counts for the 2 slides.

Urine samples were collected after 10.00 a.m. to diagnose $S$. haematobium based on detection of eggs using the filtration technique [49]. Urine samples were mixed thoroughly and 10 $\mathrm{ml}$ were drawn using a syringe and passed through the membrane where eggs were logged. Examination was done on site where detected eggs were counted and expressed as the number of eggs per $10 \mathrm{ml}$ of urine.

\section{Data management and analysis}

Data entry was done using Dbase IV (Borland International, Scotts Valley, California, USA), and a double entry system was used for quality control. Data were transferred to STATA version 8 software (Statacorp 2000, College Station, Texas, USA) for analysis. Analysis was done by generation of some frequency tables, cross tabulations, and calculation of the prevalence.

\section{Ethical considerations}

The ethical and scientific clearance was obtained from the Medical Research Coordinating Committee of the National Institute for Medical Research before the implementation of the study. The study team visited villages and schools where community leaders and teachers were respectively met and the objectives, procedure, and potential harm and benefits of the 
study were explained to them. The leaders in turn convened meetings of the community members, and the same was explained to them before the consent to participate in the study was sought. A similar procedure was followed at schools.

Schoolchildren were told that participation to the study would be voluntary and free. Any participant would be free to withdraw from the study at any time of the study period when he or she felt to do so. The decision to refuse or withdraw from the study would have no negative effect on the benefits provided during and after the study.

All subjects who would be found infected with schistosomes and intestinal helminths were treated following standard treatment guidelines using praziquantel and albendazole tablets. Participants were informed that information will be confidentially kept using code numbers instead of names of participants.

\section{RESULTS}

A total of 5,848 schoolchildren from 36 selected schools in the 4 regions of the Lake Victoria basin in Tanzania were recruited for the study (Table 1). The same numbers of girls and boys aged between 7 and 16 years from class 1 to 7 were selected for the study. Intestinal schistosomiasis caused by $S$. mansoni was prevalent in 3 regions of Kagera, Mwanza, and Mara. The highest prevalence of S. mansoni (24.8\%) was recorded in Mwanza region. Hookworms were the only helminths prevalent in all 4 regions. The prevalence of hookworms ranged from 6.7\% in Shinyanga to 32.3\% in Kagera. Ascariasis and trichuriasis were prevalent in Kagera and Mara regions only. A remarkably high prevalence of ascariasis (17.4\%) was found in Kagera region.

Urogenital schistosomiasis caused by S. haematobium was found in children from 3 regions of Mwanza, Mara, and Shinyanga but not in Kagera. Among the 3 regions, the highest prevalence (16.7\%) was recorded in Shinyanga region. The mean prevalence of both schistosomiasis and STHs in all regions ranged from low to moderate ones (Table 1).

In Kagera region, all the common intestinal helminths, namely S. mansoni, A. lumbricoides, T. trichiura, and hookworm infections were prevalent (Table 2). Bwina Primary School in Chato District recorded an extremely high prevalence of intestinal schistosomiasis of $86.5 \%$ followed by Bunena in Bukoba

Table 1. Regional mean prevalence of schistosomes and soil-transmitted helminths among schoolchildren in Lake Vitoria Basin, Tanzania

\begin{tabular}{|c|c|c|c|c|c|c|c|}
\hline \multirow{3}{*}{ Region } & \multicolumn{5}{|c|}{ Helminth eggs in stool } & \multicolumn{2}{|c|}{ S. haematobium } \\
\hline & \multirow{2}{*}{ No. exam. } & S. mansoni & \multirow{2}{*}{$\begin{array}{c}\text { Hookworms } \\
\text { No. posit. (\%) }\end{array}$} & \multirow{2}{*}{$\begin{array}{c}\text { A. lumbricoides } \\
\text { No. posit. (\%) }\end{array}$} & \multirow{2}{*}{$\begin{array}{c}\text { T. trichiura } \\
\text { No. posit. (\%) }\end{array}$} & \multirow{2}{*}{ No. exam. } & \multirow{2}{*}{ No. egg posit. in urine (\%) } \\
\hline & & No. posit. (\%) & & & & & \\
\hline Kagera & 1,012 & $171(16.9)$ & 327 (32.3) & $176(17.4)$ & $15(1.5)$ & 1,012 & $0 \quad(0.0)$ \\
\hline Mwanza & 2,146 & $532(24.8)$ & $331(15.4)$ & $0 \quad(0.0)$ & $0(0.0)$ & 2,042 & $193(9.5)$ \\
\hline Mara & 1,203 & $160(13.3)$ & 96 (8.0) & $12(1.0)$ & $3(0.2)$ & 1,203 & 58 (4.8) \\
\hline Shinyanga & 1,465 & $0 \quad(0.0)$ & 98 (6.7) & $0(0.0)$ & $0(0.0)$ & 1,591 & $265(16.7)$ \\
\hline Total & 5,826 & $863(14.8)$ & $852(14.6)$ & 188 & $18(0.3)$ & 5,848 & $516 \quad(8.8)$ \\
\hline
\end{tabular}

Table 2. Prevalence of schistosomes and soil-transmitted helminths among schoolchildren in Kagera region

\begin{tabular}{|c|c|c|c|c|c|c|}
\hline \multirow{3}{*}{ District } & \multirow{3}{*}{ Locality } & \multicolumn{5}{|c|}{ Helminth eggs in stool } \\
\hline & & \multirow{2}{*}{ No. exam. } & S. mansoni & \multirow{2}{*}{$\begin{array}{l}\text { Hookworms } \\
\text { No. posit. (\%) }\end{array}$} & \multirow{2}{*}{$\begin{array}{c}\text { A. lumbricoides } \\
\text { No. posit. (\%) }\end{array}$} & \multirow{2}{*}{$\begin{array}{c}\text { T. trichiura } \\
\text { No. posit. (\%) }\end{array}$} \\
\hline & & & No. posit. (\%) & & & \\
\hline Bukoba urban & Bunena & 125 & $21(16.8)$ & $2(1.6)$ & 32 (25.6) & $4(3.2)$ \\
\hline Muleba & Kiziramuyaga & 126 & $0 \quad(0.0)$ & $75(59.5)$ & $21(16.7)$ & $9(7.1)$ \\
\hline Muleba & Kyenshama & 125 & $0 \quad(0.0)$ & $25(20.0)$ & 32 (25.6) & $0(0.0)$ \\
\hline Muleba & Nyairigamba & 140 & $1(0.7)$ & $14(10.0)$ & $24(17.1)$ & $1(0.7)$ \\
\hline Chato & Buzirayombo & 120 & $7 \quad(5.8)$ & $44(36.7)$ & $40(33.0)$ & $0(0.0)$ \\
\hline Chato & Bwanga & 95 & $4(4.2)$ & 36 (37.9) & 27 (28.4) & $0(0.0)$ \\
\hline Chato & Bwina & 155 & $134(86.5)$ & $41(26.5)$ & $0 \quad(0.0)$ & $0(0.0)$ \\
\hline Biharamulo & Runazi & 126 & $4 \quad(3.2)$ & $90(71.4)$ & $0 \quad(0.0)$ & $2(1.6)$ \\
\hline Total & & 1,012 & $171(16.9)$ & 327 (32.3) & $176(17.4)$ & $15(1.5)$ \\
\hline
\end{tabular}


Urban District with a prevalence of $16.8 \%$, and other schools had a prevalence of less than $10 \%$. No S. haematobium positive cases were recorded in Kagera region. Hookworms were prevalent in the Kagera region. The highest prevalence was $71.4 \%$ at Runazi School followed by Kiziramuyaga 59.5\% and Bwanga $37.9 \%$ (Table 2). The prevalence of ascariasis was the highest at Buzirayombo 33.3\%, followed by Bwanga 28.4\%, Bunena 25.6\%, and Kyenshama 25.6\% (Table 2). The prevalence of trichuriasis in the region was relatively low with a mean of $1.5 \%$ where Kiziramuyaga had the highest prevalence of 7.1\%.

In Mwanza region, 3 helminth species detected included $S$. mansoni, S. haematobium, and hookworms (Table 3). The highest prevalence of $S$. mansoni infection was recorded at Nyamikoma Primary School that registered 79.2\%, followed by Bungo- nya $63.1 \%$ and Nyakaliro 63.0\% (Table 3). Bungonya Primary School had the highest prevalence of hookworms of 36.9\% followed by Mwagingh'i 34.0\% and Nyamikoma 21.3\%. The highest prevalence (32.2\%) of urogenital schistosomiasis was at Bugogo Primary School (32.3\%), and Mwaging'hi and Kigongo were the second with a prevalence of both $28.0 \%$. Lumeji was the fourth with $21.3 \%$ prevalence while the rest of schools had prevalence less than 10\% (Table 3).

The distribution of schistosomiasis and STHs in Mara region was low relative to other regions (Table 4). S. mansoni was highly prevalent at Mwisenge 36.1\%, Nyamitwebili 30.2\%, Gamasara $15.9 \%$, and Minigo $11.7 \%$. Other schools had prevalence lower than $10 \%$ (Table 4). Urinary schistosomiasis was found in 3 schools only. The prevalence was the highest (27.2\%) at

Table 3. Prevalence of helminths in stool and urine samples among schoolchildren in Mwanza region

\begin{tabular}{|c|c|c|c|c|c|c|}
\hline \multirow{3}{*}{ District } & \multirow{3}{*}{ Name of School } & \multicolumn{3}{|c|}{ Helminth eggs in stool } & \multicolumn{2}{|c|}{ S. haematobium eggs in urine } \\
\hline & & \multirow{2}{*}{ No. exam. } & S. mansoni & Hookworms & \multirow{2}{*}{ No. exam. } & \multirow{2}{*}{ No. posit. (\%) } \\
\hline & & & No. posit. (\%) & No. posit. (\%) & & \\
\hline Ilemela & Tumaini & 204 & $72(35.3)$ & $19(9.3)$ & 2 & $0 \quad(0.0)$ \\
\hline Nyamagana & Mazoezi & 175 & $19(10.9)$ & $13(7.5)$ & 65 & $0 \quad(0.0)$ \\
\hline Magu & Lumeji & 95 & $0 \quad(0.0)$ & $2(2.1)$ & 80 & $17(21.3)$ \\
\hline Magu & Nyamikoma & 178 & $141(79.2)$ & $38(21.3)$ & 161 & $8 \quad(5.0)$ \\
\hline Kwimba & Mwaging'hi & 235 & $1 \quad(0.4)$ & $80(34.0)$ & 161 & $45(28.0)$ \\
\hline Misungwi & Kigongo & 235 & $36(15.3)$ & $1 \quad(0.4)$ & 161 & $45(28.0)$ \\
\hline Geita & Bugogo & 180 & 8 (4.4) & $19(10.6)$ & 192 & $62(32.3)$ \\
\hline Geita & Chibingo & 195 & $0 \quad(0.0)$ & $59(30.3)$ & 192 & $4 \quad(2.1)$ \\
\hline Geita & Kasamwa & 129 & $0 \quad(0.0)$ & $19(14.7)$ & 151 & $1 \quad(0.7)$ \\
\hline Sengerema & Bungonya & 160 & 101 (63.1) & 59 (36.9) & 186 & $6 \quad(3.2)$ \\
\hline Sengerema & Busisi & 179 & $40(22.3)$ & $9(5.0)$ & 177 & $3(1.7)$ \\
\hline Total & & 2,146 & 577 (26.9) & $331(15.4)$ & 2,042 & 193 (9.5) \\
\hline
\end{tabular}

Table 4. Prevalence of schistosomes and soil-transmitted helminths among schoolchildren in Mara region

\begin{tabular}{|c|c|c|c|c|c|c|c|}
\hline \multirow{3}{*}{ District } & \multirow{3}{*}{ Locality } & \multicolumn{5}{|c|}{ Helminth eggs in stool } & \multirow{3}{*}{$\begin{array}{l}\begin{array}{l}\text { S. haematobium } \\
\text { eggs in urine }\end{array} \\
\text { No. posit. (\%) }\end{array}$} \\
\hline & & \multirow{2}{*}{ No. exam. } & S. mansoni & Hookworms & A. lumbricoides & T. trichiura & \\
\hline & & & No. posit. (\%) & No. posit. (\%) & No. posit. (\%) & No. posit. (\%) & \\
\hline Tarime & Gamasara & 157 & 25 (15.9) & $20(12.7)$ & $3(1.9)$ & $0(0.0)$ & $0 \quad(0.0)$ \\
\hline Tarime & Ochuna & 155 & $0 \quad(0.0)$ & $10(6.5)$ & $0(0.0)$ & $0(0.0)$ & $0(0.0)$ \\
\hline Rorya & Marasibora & 147 & $1 \quad(0.7)$ & $9(6.1)$ & $0(0.0)$ & $0(0.0)$ & $0 \quad(0.0)$ \\
\hline Rorya & Minigo & 145 & $17(11.7)$ & 28 (19.3) & $1(0.7)$ & $1(0.7)$ & $17(11.7)$ \\
\hline Musoma Urban & Mwisenge & 169 & $61(36.1)$ & $4 \quad(2.4)$ & $7(4.1)$ & $1(0.6)$ & $0 \quad(0.0)$ \\
\hline Bunda & Guta "A" & 125 & $2(1.6)$ & $3(2.4)$ & $0(0.0)$ & $0(0.0)$ & 34 (27.2) \\
\hline Bunda & Nyamitwebili & 159 & $48(30.2)$ & $18(11.3)$ & $1(0.6)$ & $0(0.0)$ & $0 \quad(0.0)$ \\
\hline Bunda & Bulamba & 146 & $6(4.1)$ & $4 \quad(2.7)$ & $0(0.0)$ & $1(0.7)$ & $4(2.7)$ \\
\hline Total & & 1,203 & $160(13.3)$ & 96 (8.0) & $12(1.0)$ & $3(0.2)$ & $58 \quad(4.8)$ \\
\hline
\end{tabular}


Table 5. Prevalence of schistosomes and soil-transmitted helminths among schoolchildren in Shinyanga region

\begin{tabular}{|c|c|c|c|c|c|}
\hline \multirow{2}{*}{ District } & \multirow{2}{*}{ Locality } & \multicolumn{2}{|c|}{ Helminth eggs in stool } & \multicolumn{2}{|c|}{ S. haematobium eggs in urine } \\
\hline & & No. exam. & Hookworm egg posit. (\%) & No. exam. & No. posit. (\%) \\
\hline Kahama & Mseki & 197 & $14(7.1)$ & 226 & $25(11.1)$ \\
\hline Kahama & Bukomela & 170 & $29(17.1)$ & 186 & $42(22.6)$ \\
\hline Bukombe & Masumbwe & 194 & 25 (12.9) & 200 & 11 (5.5) \\
\hline Shinyanga Rura & Luhumbo & 188 & $12(6.4)$ & 198 & $60(30.3)$ \\
\hline Kishapu & Songwa & 198 & $0 \quad(0.0)$ & 222 & $55(24.8)$ \\
\hline Maswa & Shishiyu & 206 & $12(5.8)$ & 214 & $40(18.7)$ \\
\hline Meatu & Ngugunu & 178 & 4 (2.2) & 186 & $14(7.5)$ \\
\hline Bariadi & Sapiwi & 134 & $2(1.5)$ & 159 & $18(11.3)$ \\
\hline Total & & 1,465 & 98 (6.7) & 1,591 & $265(16.7)$ \\
\hline
\end{tabular}

Guta "A" School followed by Minigo 11.7\% and Bulamba 2.7\%. The prevalence of hookworms in Mara region ranged from 2.4\% at Mwisenge to $19.3 \%$ at Minigo Primary School. The prevalence of trichuriasis was the lowest of all the helminths in region.

In Shinyanga region, urogenital schistosomiasis was prevalent in all schools studied (Table 5). The highest prevalence (30.3\%) was noted at Luhumbo School in Shinyanga Rural District seconded by $24.8 \%$ at Songwa Primary School in Kishapu District. Intestinal schistosomiasis was not noted in the whole study areas, whereas the hookworm prevalence was low; ranging from $0 \%$ at Songwa School to $17.1 \%$ at Bukomela School. No ascariasis nor trichuriasis cases were noted at any of the schools in Shinyanga region.

\section{DISCUSSION}

The results showed that generally the prevalence of $S$. mansoni, S. haematobium, and STHs are considerably high in the study areas. Similar observations were reported from earlier studies in Magu and Sengerema in the same areas [10,50]. However, the prevalence of $S$. mansoni in Kagera region is very low with the exception of a few pockets in Chato District which is currently in Geita region. This could be attributed to the fact that lake shores in Kagera region are open instead of bays when wind blows make the waves splash the shores making the place an unconduncive habitat for snail intermediate hosts. Moreover, some of the shores in Kagera region are formed by escarpments thus deep and less habitable by the snails. The situation is quite different from shores in Chato District which is a bay thus most of its shores are not susceptible to strong winds. The distribution of $S$. haematobium and S. mansoni along Lake Victoria is largely related to the distribution of the intermediate hosts [51]. Along the shore of the lake, members of the genus Biomphalaria, the intermediate host for S. mansoni, are common $[52,53]$ with populations living along the lake shores and islands being highly affected by $S$. mansoni as the risk of infection increases [53,54].

The shores in Chato Districts are shallow; thus very conduncive for Biomphararia snails. This is why the district recorded high prevalence of intestinal schistosomiasis. Apart from the fact that schistosomiasis is focal, the noted high prevalence of the disease in this district could be attributed to the presence of bays that experience less speedy winds and strong waves to the shores making the place unconduncive habitat for snails.

The highest prevalence of S. mansoni at Bwina Primary School in Kagera region could be attributed to the location of the study site. Bwina ward is a thin peninsular with an average width of less than $2 \mathrm{~km}$. As such, most of the area is surrounded by Lake Victoria water that is inhabited by Biomphararia species. Bwanga and Kiziramuyaga localities are close to the lake area that has small bays that are conduncive areas for the snail hosts. The absence of urogenital schistosomiasis in Kagera region could be due to the absence of ponds and streams, and the fact that no paddy cultivation is practiced in this area.

The prevalence of STH infections in Kagera region was relatively higher than that in other regions. This could be due to the difference in natural vegetations and gardens as a result of rain variations. Kagera is sunny and warm most of the year with cool evenings and rains occuring almost every morning from March through May [55]. STHs are highly affected by surface temperature [56], altitude, soil type, and rainfall [57]. This has an implication of the region having the best breeding ground of STHs as well as more people consuming semicooked vegetables that may carry helminth eggs.

In Mwanza region, the distribution of S. mansoni was similar 
to that of Mara with more happenings close to the lake and $S$. haematobium on the hinterland. The high prevalence of intestinal and urogenital schistosomisiasis in the study area was a function of the distance from Lake Victoria, the former being more prevalent at localities close to the lake, whilist the latter is more so away from it [52-54]. Moreover, in areas where the prevalence of $S$. haematobium was high, there was a significant prevalence of hookworms. The findings are in line with other studies in Magu District in Mwanza region [10-12]. The spatial distribution of $S$. haematobium is in accordance to the presence of ponds and streams as well as the wetness and warmth of the soil that are prerequisites for proliferation of the 2 helminths.

We could not easily establish why there were no Ascaris or Trichuris infections in Mwanza and Shinyanga regions that are situated in the middle of the study area. Similar findings were reported by Mazigo on 1 ward in the region [50]. Difference in soil structure and texture as well as climate among the regions could be the reasons for the difference. Kagera region on the west bordering southern Uganda and Mara region on the west which borders western Kenya have similar prevalence of the STHs as compared to Mwanza and Shinyanga regions [50,54]. The prevalence of hookworm infections, 34\% at Mwaging hi in Kwimba District, and $21.7 \%$ at nearby Nyamikoma location in Magu District, was similar to an ealier report in the same area [10]. Despite the fact that Mara region is closer to the western province in Kenya with similar types of STH infections, they differed in prevalence. This study recoded a mean regional prevalence ranging from 1\% to 8\% whereas studies in Kenya's Nyanza Province reported the prevalence of $22.9 \%$ and $17.9 \%$ for A. lumbricoides and T. trichuris, respectively $[10,50]$.

In Mara region, the high prevalence of intestinal schistosomiasis at Mwisenge and Nyamitwebili schools were associated with their being very close to the lake shore. The study team could see children sent to the lake to fetch water. The high prevalence of urogenital shistosomiasis at Guta " $\mathrm{A}$ " and Minigo could be ascribed to paddy fields, that are good habitats for the snail intermediate host of $S$. haematobium, that were enormous in the sourounding areas. In Mara region, the distribution of $S$. mansoni was similar to that of Mwanza. Moreover, in areas where schistosomiasis was high, there was a significant prevalence of hookworms. This association was reported elsewhere; these findings are in line with that from Magu District in Mwanza region and in western Kenya $[10,57,58]$. As expected, the prevalence of intestinal schistosomiasis was extremely low in
Shinyanga region that is more than $150 \mathrm{~km}$ away from the lake but had the highest prevalence of urogenital schistosomiasis.

The results showed that schistosomisasis and 3 STHs infections are co-endemic in Lake Victoria basin in Tanzania with a high probability of polyparasitism in the study participants. The prevalence of S. mansoni, S. haematobium, and STHs ranged from low to moderate in most parts of the study area. Intestinal schistosomiasis was prevalent along the Lake Victoria shores and decreased with distance from it. Conversely, the prevalence of urogenital schistosomiasis increased with distance from the Lake.

From the study findings, we recommend the followings to control schistosomiasis in the study area. First, there is a need for provision of health education to community members. This could be given in a participatory manner so that each member gets engaged in the learning process especially through peer educators. Second, study teams need to conduct regular research in order to control incidence and reinfection rates in the area by carrying out regular treatment exercises. Third, community-based provision of adequate safe water supply and sanitation facilities are imperative. Water supply could be done through construction/drilling of wells at each sub-village, institutions, and health facility.

\section{ACKNOWLEDGMENTS}

The authors are very grateful to the people of Kagera, Mwan$\mathrm{za}$, Mara, and Shinyanga for their tireless commitment to participate in the study for all 5 years running. Our heartfelt thanks go to the Government of the Republic of Korea through the Korea international Cooperation Agency (KOICA). Good Neighbors International (GNI) funded the study and provided expertise for conduction of the study from the beginning to its logical conclusion. Particular gratitude is extended to the staff of NIMR, Mwanza Research Center, and the entire members of GNI Tanzania Western Chapter for their material, moral, and technical support during the study. We would like to thank all who supported us as laboratory technologists from NIMR Mwanza whose commitment and deligency during all the stages of the study that led this study to a success.

\section{CONFLICT OF INTEREST}

There is no conflict of interest declared by any of the authors. 


\section{REFERENCES}

1. World Health Organization. Schistosomiasis: population requiring preventive chemotherapy and number of people treated in 2010. Weekly Epidemiol Rec 2012; 87: 37-44.

2. Steinmann P, Keiser J, Bos R, Tanner M, Utzinger J. Schistosomiasis and water resources development: systematic review, metaanalysis, and estimates of people at risk. Lancet Infect Dis 2006; 6: 411-425.

3. Tropical Diseases Research: Schistosomiasis diseases information. Special Programme for Research and Training in Tropical Diseases (TDR). [http://apps.who.int/tdr/svc/diseases/schistosomiasis] Accessed on 16 December 2014.

4. Crompton DWT, Montressor A, Neisheim MC, Savioli L. Controlling disease due to helminth infection. Geneva, Switzerland. World Health Organization. 2003.

5. Chitsulo L, Engels D, Montresor A, Savioli L. The global status of schistosomiasis and its control. Acta Trop 2000; 77: 41-51.

6. Mazigo HD, Nuwaha F, Kinung'hi SM, Morona D, de Moira AP, Wilson S, Heukelbach J, Dunne DW. Epidemiology and control of human schistosomiasis in Tanzania. Parasit Vectors 2012; 5: 274 .

7. Morgan JAT, Dejong RJ, Snyder SD, Mkoji GM, Loker ES. Schistosoma mansoni and Biomphalaria: past history and future trends. Parasitology 2001; 123: S211-S228.

8. Stothard JR, Kabatereine NB, Tukahebwa EM, Kazibwe F, Rollinson D, Mathieson W, Webster JP, Fenwick A. Use of circulating cathodic antigen (CCA) dipsticks for detection of intestinal and urinary schistosomiasis. Acta Trop 2006; 97: 219-228.

9. Standley CJ, Adriko M, Alinaitwe M, Kazibwe F, Kabatereine NB, Stothard JR. Intestinal schistosomiasis and soil-transmitted helminthiasis in Ugandan schoolchildren: a rapid mapping assessment. Geospat Health 2009; 4: 39-53.

10. Lwambo NJ, Siza JE, Brooker S, Bunday DA, Guyatt H. Patterns of concurrent hookworm infection and schistosomiasis in schoolchildren in Tanzania. Trans R Soc Trop Med Hyg 1999; 93: 497502.

11. Kinung'hi SM, Magnussen P, Kishamawe C, Todd J, Vennervald BJ. The impact of anthelmintic treatment intervention on malaria infection and anaemia in school and preschool children in Magu district, Tanzania: an open label randomised intervention trial. BMC Infect Dis 2015; 15: 136.

12. Brooker S, Kabatereine NB, Gyapong JO, Stothard JR, Utzinger J. Rapid mapping of schistosomiasis and other neglected tropical diseases in the context of integrated control programmes in Africa. Parasitology 2009; 136: 1707-1718.

13. Verani JR, Abudho B, Montgomery SP, Mwinzi PN, Shane HL, Butler SE, Karanja DM, Secor WE. Schistosomiasis among young children in Usoma, Kenya. Am J Trop Med Hyg. 2011; 84: 787791.

14. Odogwu SE, Ramamurthy NK, Kabatereine NB, Kazibwe F, Tukahebwa E, Webster JP, Fenwick A, Stothard JR. Schistosoma man- soni in infants (aged <3 years) along the Ugandan shoreline of Lake Victoria. Ann Trop Med Parasitol 2006; 100: 315-326.

15. Stothard JR, Kabatereine NB, Tukahebwa EM, Kazibwe F, Mathieson W, Webster JP, Fenwick A. Field evaluation of the Meade Readiview handheld microscope for diagnosis of intestinal schistosomiasis in Ugandan school children. Am J Trop Med Hyg. 2005; 73: 949-955.

16. Smith JH, Christie JD. The pathobiology of Schistosoma haematobium infection in humans. Hum Pathol 1986; 17: 333-345.

17. Warren KS. The pathology, pathobiology and pathogenesis of schistosomiasis. Nature 1978; 273: 609-612.

18. King CH, Dickman K, Tisch DJ. Reassessment of the cost of chronic helmintic infection: a meta-analysis of disability-related outcomes in endemic schistosomiasis. Lancet 2005; 365: 15611569.

19. Jukes MC, Nokes CA, Alcock KJ, Lambo JK, Kihamia C, Ngorosho N, Mbise A, Lorri W, Yona E, Mwanri L, Baddeley AD, Hall A, Bundy DA, Partnership for Child Development. Heavy schistosomiasis associated with poor short-term memory and slower reaction times in Tanzanian schoolchildren. Trop Med Int Health 2002; 7: 104-117.

20. Ndamba J, Makaza N, Munjoma M, Gomo E, Kaondera KC. The physical fitness and work performance of agricultural workers infected with Schistosoma mansoni in Zimbabwe. Ann Trop Med Parasitol 1993; 87: 553-561.

21. Collins KJ, Brotherhood RJ, Davies CT, Dore C, Hackett AJ, Imms FJ, Musgrove J, Weiner JS, Amin MA, El Karim M, Ismail HM, Omer AH, Sukkar MY. Physiological performance and work capacity of Sudanese cane cutters with Schistosoma mansoni infection. Am J Trop Med Hyg 1976; 25: 410-421.

22. Fenwick A, Figenschou BH. The effect of Schistosoma mansoni infection of the productivity of cane cutters on a sugar estate in Tanzania. Bull World Health Organ 1972; 47: 567-572.

23. Montresor A, Crompton DWT, Hall A, Bundy DAP. Guidelines for the evaluation of soil-transmitted helminthiasis and schistosomiasis at community level, WHO/CTD/SIP/98.1. Geneva, Switzerland. World Health Organization. 1998.

24. Brooker S, Clements AC, Bundy DA. Global epidemiology, ecology and control of soil-transmitted helminth infection. Adv Parasitol 2006; 62: 221-261.

25. Hotez PJ, Ehrenberg JP. Escalating the global fight against neglected tropical diseases through interventions in the Asia Pacific region. Adv Parasitol 2010; 72: 31-53.

26. World Health Organization. Soil-transmitted helminthiases. Eliminating soil-transmitted helminthiases as a public health problem in children. Progress report 2001-2010 and strategic plan 20112020. Geneva, Switzerland. World Health Organisation. 2012.

27. Hotez PJ, Fenwick A, Savioli L, Molyneux DH. Rescuing the bottom billion through control of neglected tropical diseases. Lancet 2009; 373: 1570-1575.

28. Ajanga A, Lwambo NJS, Blair L, Nyandindi U, Fenwick A, Brooker S. Schistosoma mansoni in pregnancy and associations with anaemia in northwest, Tanzania. Trans R Soc Trop Med Hyg 2006; 100: 
59-63.

29. Brooker S, Miguel EA, Moulin S, Luoba AI, Bundy DA, Kremer M. Epidemiology of single and multiple species of helminth infections among school children in Busia District, Kenya. East Afr Med J 2000; 77: 157-161.

30. Clements AC, Deville MA, Ndayishimiye O, Brooker S, Fenwick A. Spatial co-distribution of neglected tropical diseases in the east African great lakes region: revisiting the justification for integrated control. Trop Med Int Health 2010; 15: 198-207.

31. Handzel T, Karanja DM, Addiss DG, Hightower AW, Rosen DH, Colley DG, Andove J, Slutsker L, Evansecor W. Geographic distribution of schistosomiasis and soil-transmitted helminths in Western Kenya: implication for anthelminthic mass treatment. Am J Trop Med Hyg 2003; 69: 318-323.

32. Nasr NA, Al-Mekhlafi HM, Ahmed A, Roslan MA, Bulgiba A. Towards an effective control programme of soil-transmitted helminth infections among Orang Asli in rural Malaysia. Part 1: prevalence and associated key factors. Parasit Vectors 2013; 6: 27.

33. Brooker S, Bundy DAP. Soil-transmitted helminths (geohelminths) In Cook GC, Zumla AI, eds, Manson's Tropical Diseases. London, UK. Elsevier. 2008, pp. 848-853.

34. Hotez PJ, Bundy DAP, Beegle K, Brooker S, Drake L, de Silva N, Montresor A, Engels D, Jukes M, Chitsulo L, Chow J, Laxminarayan R, Michaud C, Bethony J, Oliveira R, Xiao SH, Fenwick A, Savioli L. Helminth Infections: soil-transmitted helminth infections and schistosomiasis. In Jamison DT, Breman J, Measham AR, Alleyne G, Claeson M, Evans DB, Jha P, Mills A, Musgrove P, eds, Disease Control Priorities in Developing Countries. New York, USA. Oxford University Press. 2006, pp. 467-497.

35. Keiser J, Utzinger J. Efficacy of current drugs against soil-transmitted helminth infections: systematic review and meta-analysis. JAMA 2008; 299: 1937-1948.

36. Taylor-Robinson DC, Jones AP, Garner P. Deworming drugs for treating soil-transmitted intestinal worms in children: effects on growth and school performance. Cochrane Database Syst Rev 2007: (4) CD000371.

37. Crompton DW, Nesheim MC. Nutritional impact of intestinal helminthiasis during the human life cycle. Ann Rev Nutr 2002; 22: 35-59.

38. Hotez PJ, Brooker S, Bethony JM, Bottazzi ME, Loukas A, Xiao S. Hookworm infection. N Engl J Med 2004; 351: 799-807.

39. Doenhoff MJ, Cioli D, Utzinger J. Praziquantel: mechanisms of action, resistance and new derivatives for schistosomiasis. Curr Opin Infect Dis 2008; 21: 659-667.

40. Fleming FM, Fenwick A, Tukahebwa EM, Lubanga RG, Namwangye H, Zaramba S, Kabatereine NB. Process evaluation of schistosomiasis control in Uganda, 2003 to 2006: perceptions, attitudes and constraints of a national programme. Parasitology 2009; 136: 1759-1969.

41. Hotez PJ, Bundy DAP, Beegle K, Brooker S, Drake L, de Silva N, et. al. Helminth infections: soil-transmitted helminth infections and schistosomiasis. In Jamison DT, Breman JG, Measham AR, Alleyne G, Claeson M, Evans DB, Jha P, Mills A, Musgrove P, eds,
Disease Control Priorities in Developing Countries. 2nd ed. Washington DC, USA. World Bank. 2006.

42. Kamel M, Ghafar Y, Foda N, Khashab S. Impact of type and stage of schistosomiasis on quality of life and productivity of infected workers. J Egypt Soc Parasitol 2001; 3: 153-167.

43. Conteh L, Engels T, Molyneux DH. Socioeconomic aspects of neglected tropical diseases. Lancet 2010; 375: 239-247.

44. Molyneux DH, Malecela MN. Neglected tropical diseases and the millennium development goals: why the "other diseases" matter: reality versus rhetoric. Parasit Vectors 2011; 4: 234.

45. Fincham JE, Markus MB, Adams VJ. Could control of soil-transmitted helminthic infection influence the HIV/AIDS pandemic. Acta Trop 2003; 86: 315-333.

46. Druilhe P, Tall A, Sokhna C. Worms can worsen malaria: towards a new means to roll back malaria? Trends Parasitol 2005; 21: 359362.

47. Hotez PJ, Molyneux DH, Fenwick A, Ottesen E, Ehrlich Sachs S, Sachs JD. Incorporating a rapid-impact package for neglected tropical diseases with programs for HIV/AIDS, tuberculosis, and malaria. PLoS Med 2006; 3: e102.

48. Katz N, Chaves A, Pellegrino J. A simple device for quantitative stool thick-smear technique in schistosomiasis mansoni. Rev Inst Med Trop Sao Paulo 1972; 14: 397-400.

49. World Health Organization. Prevention and control of schistosomiasis and soil-transmitted helminthiasis: report of a WHO expert committee. Geneva, Switzerland. World Health Organization. 2001.

50. Mazigo HD, Waihenya R, Lwambo NJS, Mnyone LL, Mahande AM, Seni J, Zinga M, Kapesa A, Kweka EJ, Mshana SE, Heukelbach J, Mkoji GM. Co-infections with Plasmodium falciparum, Schistosoma mansoni and intestinal helminths among schoolchildren in endemic areas of northwestern Tanzania. Parasit Vectors 2010; 3: 44.

51. Jordan P, Webbe G. Epidemiology. In Schistosomiasis, Epidemiology, Treatment and Control. London, UK. Heinemann Medical Books. 1982, pp. 227-229.

52. Magendantz M. The biology of Biomphalaria choanomphala and B. sudanica in relation to their role in the transmission of Schistosoma mansoni in Lake Victoria at Mwanza, Tanzania. Bull World Health Organ 1972; 47: 331-342.

53. Marti HP, Tanner HP, DegreÂmont AA, Freyvogel TA. Studies on the ecology of Bulinus globosus, the intermediate host of Schistosoma haematobium, the Ifakara area, Tanzania. Acta Trop 1985; 42: 171-187.

54. Mwinzi PN, Montgomery SP, Owaga CO, Mwanje M, Muok EM, Ayisi JG, Laserson KF, Muchiri EM, Secor WE, Karanja DM. Integrated community-directed intervention for schistosomiasis and soil transmitted helminths in western Kenya-a pilot study. Parasit Vectors 2012; 5: 182.

55. Kariuki HC, Clennon JA, Brady MS, Kitron U, Sturrock RF, Ouma JH, Ndzovu ST, Mungai P, Hoffman O, Hamburger J, Pellegrini C, Muchiri EM, King CH. Distribution patterns and cercarial shedding of Bulinus nasutus and other snails in the Msambweni area, 
Coast Province, Kenya. Am J Trop Med Hyg 2004; 70: 449-456.

56. Brooker S, Singhasivanon P, Waikagul J, Supavej S, Kojima S, Takeuchi T, Luong TV, Looareesuwan S. Mapping soil-transmitted helminths in Southeast Asia and implications for parasite control. Southeast Asian J Trop Med Public Health 2003; 34: 24-36.

57. Appleton CC, Gouws E. The distribution of common intestinal nematodes along an altitudinal transect in KwaZulu-Natal,
South Africa. Ann Trop Med Parasitol 1996; 90: 181-188.

58. Kabatereine NB, Brooker S, Koukounari A, Kazibwe F, Tukahebwa EM, Fleming FM, Zhang YB, Webster JP, Stothard JR, Fenwick A. Impact of a national helminth control programme on infection and morbidity in Ugandan schoolchildren. Bull World Health Organ 2007; 85: 91-99. 